\title{
Economic analysis of pharmacist-administered influenza vaccines in Ontario, Canada
}

This article was published in the following Dove Press journal:

ClinicoEconomics and Outcomes Research

\author{
Daria J O'Reilly',2 \\ Gord Blackhouse ${ }^{1,2}$ \\ Sheri Burns ${ }^{2}$ \\ James M Bowen ${ }^{1,2}$ \\ Natasha Burke ${ }^{1,2}$ \\ Jeff Mehltretter ${ }^{3}$ \\ Nancy MWaite ${ }^{4}$ \\ Sherilyn KD Houle ${ }^{4}$
}

'Department of Health Research Methods, Evidence, and Impact, Faculty of Health Sciences, McMaster University, Hamilton, ON, Canada;

${ }^{2}$ Programs for Assessment of

Technology in Health (PATH),

The Research Institute of St.

Joe's Hamilton, Hamilton, ON,

Canada; ${ }^{3}$ Neighbourhood Pharmacy

Association of Canada, Toronto, ON,

Canada; ${ }^{4}$ School of Pharmacy, Faculty

of Science, University of Waterloo,

Waterloo, ON, Canada
Correspondence: Daria J O'Reilly Department of Health Research Methods, Evidence, and Impact, Faculty of Health Sciences, 1280 Main Street West, McMaster University, CRL, 2nd floor, Hamilton, ON L8S 4KI, Canada

$\mathrm{Tel}+\mathrm{I} 5195880226$

Email oreilld@mcmaster.ca
Objective: The aim of this study was to evaluate the impact of pharmacist administration of influenza vaccine in Ontario on: 1) vaccination-associated costs related to the number of people vaccinated; 2) annual influenza-related outcomes and costs; and 3) change in productivity costs. Methods: Using available data for Ontario, the total number of vaccinations given by providers in the 2011/12 influenza season (pre) was compared to the 2013/14 influenza season (post). Vaccine costs and provider fees for administration were assigned for both periods. An economic model was created to estimate the impact of the change in influenza vaccination volume on influenza-related outcomes and on the health care costs associated with treating influenza-related outcomes. Productivity costs due to both time off work due to getting vaccinated and influenza illness were considered. One-way sensitivity analysis was used to assess parameter uncertainty. Results: The number of vaccinations received by Ontarians increased by 448,000 (3\% of the population), with pharmacists vaccinating approximately 765,000 people/year. The increased cost to the Ontario Ministry of Health and Long-term Care was $\$ 6.3$ million, while the money saved due to reduced influenza-related outcome costs was $\$ 763,158$. Productivity losses were reduced by $\$ 4.5$ million and $\$ 3.4$ million for the time invested to get vaccinated and time off work due to influenza illness, respectively.

Conclusion: After two influenza seasons, following the introduction of pharmacist-administered influenza vaccinations, there was a net immunization increase of almost 450,000, which potentially saved $\$ 2.3$ million in direct health care costs and lost productivity in the province. Keywords: universal influenza vaccination, costs, pharmacist, productivity, immunization

\section{Introduction}

Influenza is a major cause of morbidity and mortality. On average, 12,200 hospitalizations and 3,500 influenza-related deaths occur annually in Canada. ${ }^{1}$ Increasing influenza vaccinations can lead to considerable cost savings through a reduction in the utilization of health care services associated with influenza. An estimated 2.5\% increase in the influenza vaccination rate of elderly Canadians results in a \$16 million reduction in health care costs. ${ }^{2}$

In October 2012, as an initiative to increase accessibility to influenza vaccines and increase overall vaccination rates in Ontario, Canada (population 13.9 million $^{3}$ ), the Universal Influenza Immunization Program (UIIP) authorized trained pharmacists to administer influenza vaccines to those aged 5 years and older. ${ }^{4}$ In the second influenza season following the implementation of pharmacy-administered influenza vaccinations, 764,922 individuals were vaccinated by community pharmacists. ${ }^{5}$ As pharmacists continue to expand their scope of practice, ${ }^{6}$ it is important to estimate the economic 
impact of pharmacist-administered vaccinations. Specifically, we evaluated the resource use and costs associated with the introduction of pharmacist-administered influenza vaccinations in Ontario.

\section{Methods}

The economic analysis was composed of the following three components: 1) evaluation of vaccination-associated costs due to the changing number of people vaccinated; 2) impact of the change in vaccinations on influenza-related outcomes and costs; and 3) productivity costs associated with vaccination in the pre- and post-pharmacist-administered influenza vaccination periods. The main analysis was conducted from a public payer perspective, with a societal perspective considered in the productivity-related analysis. Targeted literature searches were conducted to identify relevant information for the clinical and economic data required to populate the economic model. All costs are reported in 2016 Canadian dollars. All analyses were conducted in Microsoft Excel (2011).

\section{Changes in vaccination-associated costs}

Pharmacist and physician billing data and public health influenza vaccination distribution data for two influenza seasons $(2011 / 12 \text { and } 2013 / 14)^{7,8}$ were available and used to determine the number of influenza vaccinations administered by providers. The goal was to examine the number of vaccinations administered by pharmacists in community pharmacies relative to those given by physicians and public health nurses and to estimate the costs of administration before and after the inclusion of pharmacists in the UIIP.

The 2011/12 influenza season was prior to the inclusion of pharmacists and thus represented the "pre" pharmacist vaccination period. ${ }^{7}$ Since only a fraction of Ontario pharmacists participated in the first year of the program (2012/13) owing to the training requirements and approvals needed to participate, the 2013/14 influenza season was the first year of widespread adoption of pharmacist-administered vaccinations and represented the "post" pharmacist vaccination period. ${ }^{7}$ The change in the number of vaccinations administered over this period was calculated and categorized by health care provider.

Vaccination-associated costs were calculated by multiplying the vaccine dose cost by the number of vaccinations by the provider combined with the professional billing fee for vaccine administration.

Wholesale vaccine costs for the five influenza vaccines available in Ontario (ie, Agriflu ${ }^{\circledR}$, Fluviral $^{\circledR}$, Influvac $^{\circledR}$, Fluad $^{\circledR}$, and Fluzone Quadrivalent ${ }^{\circledR}$ ) were obtained from an independent community pharmacy. The average cost per dose was cal- culated to be $\$ 9.45$. To account for the tendering of vaccines, a $42.5 \%$ reduction was applied, representing the median of the $25-60 \%$ discount in market price provided to the Ontario Ministry of Health and Long-Term Care across manufacturers. The final average vaccine cost per dose was $\$ 5.43$.

For the physician billing fees for influenza vaccine administration, we assumed that the following two scenarios were possible: 1) the patient receives the vaccine during a physician visit concerning another matter, with a billing cost for vaccine administration of $\$ 4.50$ (intervention code G590) ${ }^{9}$; and 2) the physician visit is solely for the vaccination, with a billing cost of $\$ 9.60$ (intervention codes G590 [\$4.50] and G700 [\$5.10] $)^{9}$. It was assumed that $75 \%$ of the physicianprovided vaccinations were given during visits that were solely for vaccination. ${ }^{2}$ Thus, we used a weighted average of $\$ 8.33$ per vaccination for physicians.

The pharmacist reimbursement fee was $\$ 7.50,{ }^{10}$ and the fee per vaccination provided by a public health nurses was $\$ 5.00 .^{11}$ For providers that were classified as "Other", the vaccination fee was assumed to be the same as for public health nurses. The resulting costs associated with the influenza vaccination by each health care provider were as follows: physicians, \$13.76; pharmacists, $\$ 12.93$; and public health unit and other nurses, $\$ 10.43$.

\section{Impact of change in vaccinations on influenza-related outcomes and costs}

A mathematical model was created in Excel to estimate the impact of the change in influenza vaccination volume in Ontario on influenza-related outcomes and associated health care costs. Variables and assumptions used in the model are summarized in Table 1. Baseline rates of influenza-related deaths and hospitalizations were based on influenza surveillance data for Ontario. ${ }^{12-14}$ Annual rates of influenza-related physician visits and emergency room visits were based on Ontario-specific data. ${ }^{7}$ The annual probability of contracting influenza was estimated for those aged 5-64 years and those aged $\geq 65$ years, based on published data. ${ }^{15}$

It was assumed that receiving a vaccination would reduce the rate of all influenza-related outcomes by a factor of 0.69 for individuals aged 5-64 years and by 0.60 for individuals aged $\geq 65$ years. $^{15}$

The baseline risk of each of the influenza-related outcomes was multiplied by the relative reduction of influenza outcomes from vaccinations to estimate the number of outcomes avoided per 100,000 people vaccinated. For example, the baseline number of influenza-related hospitalizations for people aged $\geq 65$ years was 115.07 per 100,000 individuals. ${ }^{12-14}$ This was multiplied by the relative reduction of 
influenza outcomes from vaccination for this age category (0.60) to estimate the number of hospitalizations avoided $(115.07 \times 0.60=64.09)$. Similar calculations were used to estimate the number of hospitalizations avoided per 100,000 individuals aged $5-64$ years $(10.88 \times 0.69=7.51)$.

Based on unpublished data from the Ontario Pharmacy Evidence Network (OPEN) on the age distribution of individuals vaccinated in pharmacies, we assumed that $73.4 \%$ of the individuals vaccinated were aged 5-64 years, while $26.6 \%$ were aged $\geq 65$ years. To estimate the impact of the change in number of influenza vaccinations on influenza outcomes, the number of outcomes avoided per 100,000 individuals by age category was weighted by the proportion of individuals vaccinated by age category. The age-weighted number of outcomes avoided per 100,000 individuals was further increased by a factor reflecting the change in number of patients vaccinated following the introduction of the pharmacist vaccination program.

To estimate the health care savings from avoiding the various influenza-related outcomes, the number of each type of influenza outcome avoided was multiplied by the cost per outcome $^{16}$ (Table 1) and inflated to 2016 Canadian dollars using the health care component of the Canadian consumer price index. ${ }^{17}$

\section{Productivity costs}

In addition to vaccine and health care resource costs, estimates were made on the impact of the pharmacist-administered vaccinations on productivity costs. The following two situations were considered in this analysis: 1) time invested related to time taken off from work to get vaccinated; and 2) time lost related to time missed from work owing to illness from catching influenza.

\section{Time taken off from work to get vaccinated}

To calculate the change in productivity costs due to time invested, the provider-specific change in the number of vaccinations was multiplied by provider-specific per-vaccination productivity costs. These were estimated considering: 1) the percentage of vaccinations assumed to occur during work hours; 2) the percentage of individuals vaccinated who are in the workforce; 3 ) the number of hours taken off work for an influenza vaccination; and 4) the average hourly wage in Ontario (Table 1).

Table I Baseline model parameters

\begin{tabular}{|c|c|c|c|}
\hline \multirow[t]{2}{*}{ Variable } & \multicolumn{2}{|l|}{ Value (range) } & \multirow[t]{2}{*}{ Source } \\
\hline & $\begin{array}{l}\text { Age 5-64 } \\
\text { years }\end{array}$ & $\begin{array}{l}\text { Age } \\
\geq 65 \text { years }\end{array}$ & \\
\hline Probability of contracting influenza & $\begin{array}{l}0.06(0.01 \\
0.15)\end{array}$ & $\begin{array}{l}0.09 \\
(0.02,0.20)\end{array}$ & Prosser et $\mathrm{al}^{15}$ \\
\hline Reduction in influenza outcomes due to vaccination & $\begin{array}{l}0.69(0.42 \\
0.90)\end{array}$ & $\begin{array}{l}0.60 \\
(0.29,0.87)\end{array}$ & Prosser et $\mathrm{al}^{15}$ \\
\hline \multicolumn{4}{|l|}{ Baseline outcome counts (per 100,000 ) } \\
\hline Influenza-related physician office visits & $\begin{array}{l}\text { I34.II (I3I.95, } \\
\text { I36.30) }\end{array}$ & $\begin{array}{l}225.21 \\
(219.00,235.50)\end{array}$ & Kwong et $\mathrm{al}^{7}$ \\
\hline Influenza-related emergency department visits & $\begin{array}{l}24.89(23.98 \\
25.83)\end{array}$ & $\begin{array}{l}101.34 \\
(97.19,105.58)\end{array}$ & Kwong et $\mathrm{al}^{7}$ \\
\hline Influenza-related hospitalizations & $\begin{array}{l}10.88^{\mathrm{a}}(10.27 \\
|| \mathrm{I} .5 \mathrm{I})\end{array}$ & $\begin{array}{l}\text { II5.07a } \\
(110.64,119.58)\end{array}$ & Public Health Ontario ${ }^{12-14}$ \\
\hline Influenza-related deaths & $\begin{array}{l}0.49^{a} \\
(0.36,0.63)\end{array}$ & $\begin{array}{l}12.13^{\mathrm{a}} \\
(0.12,0.14)\end{array}$ & Public Health Ontario ${ }^{12-14}$ \\
\hline \multicolumn{4}{|l|}{ Productivity } \\
\hline Proportion of individuals who are employed & $\begin{array}{l}0.63(0.62 \\
0.64)\end{array}$ & $\begin{array}{l}0.13 \\
(0.12,0.14)\end{array}$ & Statistics Canada ${ }^{20}$ \\
\hline Proportion of vaccinations that result in time taken off & \multicolumn{2}{|c|}{ Pharmacist: $0 \%(0 \%, 50 \%)$} & Assumption \\
\hline work (by provider) ${ }^{\mathrm{b}}$ & \multicolumn{2}{|c|}{ Physician: $100 \%$ (100\%, 50\%) } & Assumption \\
\hline & \multicolumn{2}{|c|}{ Others: $50 \%(100 \%, 50 \%)$} & Region of Waterloo Public Health ${ }^{18,19}$ \\
\hline Hours taken off work per vaccination & \multicolumn{2}{|c|}{$2(0.5,3.0)$} & Ray et $\mathrm{al}^{2 !}$ \\
\hline Proportion of influenza cases that result in time off work ${ }^{b}$ & \multicolumn{2}{|l|}{$\mathrm{I} .0(0.5, \mathrm{I} .0)$} & Assumption \\
\hline Hours taken off work per influenza case & \multicolumn{2}{|l|}{$14^{10,18}$} & Schanzer et $\mathrm{al}^{22}$ \\
\hline Average hourly wage $(\$)$ & \multicolumn{2}{|c|}{$26.11(13.31,38.90)$} & Statistics Canada ${ }^{32}$ \\
\hline \multicolumn{4}{|l|}{ Health care resource unit costs $(\$)$} \\
\hline Physician office visit & \multicolumn{2}{|l|}{$36(2 I . I I, 54.60)$} & Sander et $\mathrm{al}^{16}$ \\
\hline Emergency room visit & \multicolumn{2}{|l|}{$229(132,354)$} & Sander et $\mathrm{al}^{16}$ \\
\hline Influenza hospitalization & \multicolumn{2}{|c|}{$6,689(3,870,10,342)$} & Sander et $\mathrm{al}^{16}$ \\
\hline
\end{tabular}

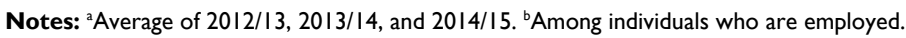


To estimate the annual change in productivity costs due to time lost, the number of annual influenza cases avoided after the inclusion of pharmacists in the UIIP was multiplied by the per-influenza case productivity cost. The per-influenza case productivity cost integrated: 1 ) the percentage of influenza illnesses that would lead to a work absence (for those who are employed); 2) the percentage of individuals who were vaccinated that are in the workforce; 3) the number of hours taken off work for influenza illness; and 4) the average hourly wage in Ontario.

Given that pharmacies in Ontario are generally open outside regular work hours (ie, evenings and weekends), it was assumed that pharmacist-administered influenza vaccinations would not require taking time off from work. Since family physician offices are primarily open during regular work hours, it was assumed that all the physician-administered influenza vaccinations would require time off work. A review of the hours of operation of public health influenza vaccination clinics in the region of Waterloo, Ontario, in the years $2011 / 12^{18}$ and $2012 / 13^{19}$ found that the clinics were open on weekdays between 2:00 pm and 8:00 pm. Assuming that the workday ends at 5:00 pm, it was assumed that half of the influenza clinic hours occurred during regular work hours. Therefore, it was assumed that half of the public health nurseadministered influenza vaccinations occurred during regular work hours. It was also assumed that half of the vaccinations by "other" providers occurred during regular work hours.

Data from Statistics Canada ${ }^{20}$ were used to derive the percentage of the population employed by age category (5-64 years, $\geq 65$ years). It was assumed that no individuals under the age of 15 years would be employed full time. These data were combined with Ontario 2016 population census data ${ }^{3}$ to estimate that $63 \%$ of the individuals aged $5-64$ years are employed while $13 \%$ of the individuals aged $\geq 65$ years are employed full time. It was assumed that every influenza vaccination that resulted in a work absence would result in 2 hours of productivity loss. ${ }^{21}$

Assuming that all vaccinations administered by a pharmacist were done outside work hours and that all vaccinations administered by physicians were done within work hours would result in a reduction in productivity costs being incurred and thus favor the intervention and the best case scenario.

\section{Time lost due to influenza-related illness}

It was assumed that all influenza episodes result in a work absence among people who were employed for an average of 14 hours per case. ${ }^{22}$

\section{Scenario and sensitivity analyses}

Probabilistic sensitivity analysis (PSA) was conducted to assess the overall uncertainty of the cost estimates. In PSA, the model results are simulated a large number of times. In each simulation, different values of the model inputs were chosen based on specified parameters and distributions. For the current analysis, beta distributions were applied to proportion-based variables, gamma distributions were applied to costs, and normal distributions were applied to non-proportion-based continuous variables (eg, hours of work per influenza illness). Parameter values for each variable were approximated based on the findings from their source reference (eg, variation, number of patients). For cost variables with no information on variation, the lower and upper ranges were assumed to correspond to a $25 \%$ change in costs. The ranges provided in Table 1 represent the 95\% CIs resulting from the parameters used for each variable in the PSA. Variables based solely on assumptions were not varied in the PSA. The model results were simulated 1,000 times.

In a hypothetical scenario analysis, the changes in influenza-related health care outcomes and costs were estimated by altering the proportion of patients vaccinated in the $\geq 65$ age category. In the base case, the percentage of people vaccinated by age category was based on what was observed among pharmacist-provided vaccinations (73.4\% aged 5-64 years, $26.6 \%$ aged $\geq 65$ years) (unpublished data from OPEN). In the scenario analysis, this value was replaced with the percentage of individuals vaccinated by age category observed among physician-administered vaccinations (ie, 59.1\% aged 5-64 years, $40.9 \%$ aged $\geq 65$ years) (unpublished data from OPEN). By reducing the proportion of younger people getting vaccinated, it reduces the number of people taking time off work vaccination as well as reducing the time taken off work if they contract influenza compared with the base case. This would essentially result in the intervention not being as favorable (ie, less money saved due to productivity losses).

In addition, one-way sensitivity analyses were conducted by changing one model variable at a time. The lower and upper range of values used in each one-way sensitivity analysis is shown in Table 1. These ranges correspond to those used in the PSA. The one-way sensitivity analyses are presented in a tornado diagram, which plots the range of incremental costs estimated when each variable is varied on its own.

\section{Results \\ Changes in number of people vaccinated and vaccination-associated costs}

From the available data, the number of influenza vaccinations administered to Ontarians in the year before pharmacist involvement $(2011 / 12)$ was 2.6 million, while in the postpharmacist-administered vaccination period $(2013 / 14)$, the 
number was 3.1 million, a net increase of 448,278. Pharmacists administered approximately 765,000 vaccinations, while the number of vaccinations administered by physicians, public health, and others decreased (Figure 1).

The estimated incremental increase in direct expenditures associated with vaccinating the additional 448,278 people was $\$ 6.3$ million (Table 2). This value includes both the cost of the vaccine and the billing fees for administering the vaccine by the health care provider.

\section{Impact of change in vaccinations on influenza-related outcomes and costs}

Given that the number of hospitalizations avoided per 100,000 individuals was estimated to be 7.51 for 5-64-year olds and 64.09 for those aged $\geq 65$ years, the age-weighted number of hospitalizations avoided owing to vaccinations was estimated to be $(7.51 \times 73.4 \%)+(64.09 \times 26.6 \%)=23.9$. This number was further increased by a factor of 4.448278 to reflect the impact of total change in annual vaccinations $(448,278)$ in the post period on influenza-related hospitalizations $(23.9 \times 4.44278=107.13)$ (Table 3$)$. The increased number of vaccinations corresponded to 20,063 fewer influenza cases.

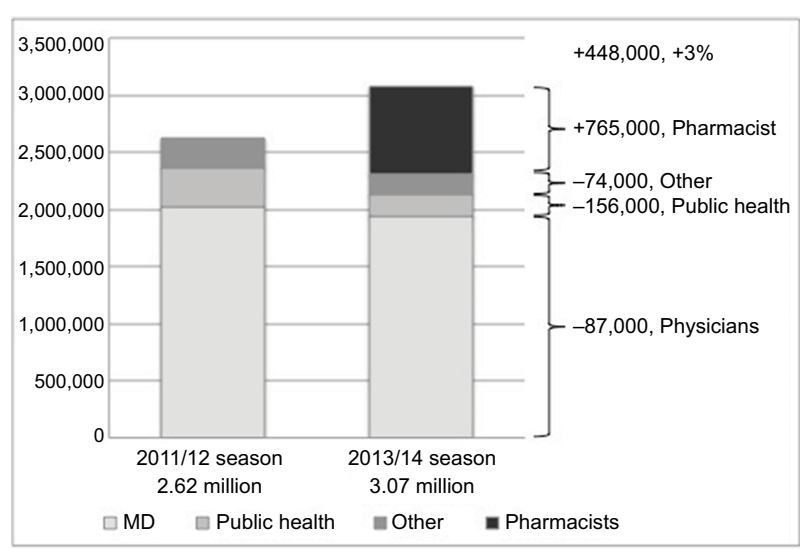

Figure I Influenza vaccinations by health care provider.

Table 2 Change in influenza vaccination expenditure 201 I/I 2 vs $2013 / 14$ in Ontario

\begin{tabular}{llll}
\hline Provider & \multicolumn{4}{l}{ Change in expenditures (\$) } \\
\cline { 2 - 4 } & Total & Vaccine only & Billing fee only \\
\hline Pharmacist & $9,893,310$ & $4,156,395$ & $5,736,915$ \\
Physician & $-1,192,072$ & $-470,786$ & $-721,286$ \\
Public health & $-1,624,504$ & $-846,019$ & $-778,485$ \\
Others & $-775,290$ & $-403,760$ & $-371,530$ \\
Total & $\mathbf{6 , 3 0 1 , 4 4 4}$ & $\mathbf{2 , 4 3 5 , 8 3 1}$ & $\mathbf{3 , 8 6 5 , 6 1 4}$ \\
\hline
\end{tabular}

Given the reductions in health care service utilization, the corresponding cost saving in direct health care costs was estimated to be about $\$ 717,000$ for influenza-related hospitalizations (Table 3 ). The increase in vaccinations translated into an overall saving of $\$ 763,158$ when combining doctor's office visits, emergency room visits, and hospitalizations.

\section{Productivity costs}

\section{Time taken off from work to get vaccinated}

With a large proportion of people using pharmacists' services to get vaccinated and the likelihood of taking fewer hours off work relative to the period before pharmacists were permitted to administer influenza vaccines, the estimated productivity cost of the time invested was reduced by $\$ 4.5$ million (Table 4).

\section{Time lost due to influenza-related illness}

Based on the assumption of 14 hours' lost work time per influenza case, and adjusting for the age-weighted proportion of the population employed, it was estimated that 20,063 influenza cases avoided by the increase in the number of people vaccinated would result in 131,007 fewer hours taken off work and productivity savings of $\$ 3.4$ million in the program year.

\section{Total change in annual costs}

Compared to the 2011/12 influenza season, the incremental cost in administering an additional 448,278 vaccinations was $\$ 5.5$ million. When the productivity costs are taken into account, the total estimated reduction in costs was approximately $\$ 2.3$ million (Table 5).

\section{Scenario analysis}

Altering the proportion of patients vaccinated in each age category

If the percentage of those vaccinated by a pharmacist who were elderly ( $\geq 65$ years of age) increased from $26.6 \%$ to $40.9 \%$, there would be a greater reduction in influenza-related outcomes and an additional savings of almost $\$ 270,000$ in influenza-related health care costs. However, this also resulted in $\$ 423,000$ less productivity cost savings than the base-case scenario.

\section{Probabilistic and one-way sensitivity analyses}

Based on the 1,000 PSA simulations, there was a $75 \%$ probability that allowing administration of the influenza vaccinations by a pharmacist would lead to overall cost 
Table 3 Influenza-related outcomes avoided per 100,000 and direct health care costs saved based on increase in vaccinations, $201 \mathrm{I} / \mathrm{I} 2$ vs $2013 / 14$

\begin{tabular}{lll}
\hline Outcome & Events avoided & Costs saved (\$) \\
\hline Influenza cases & 20,063 & - \\
Influenza-related deaths & 9.8 & - \\
Influenza-related office visits & 466 & 16,986 \\
Influenza-related emergency department visits & 129 & 29,595 \\
Influenza-related hospitalizations & 107 & 716,577 \\
Total health care resource dollars saved & & $\mathbf{7 6 3 , 1 5 8}$ \\
\hline
\end{tabular}

Table 4 Change in productivity costs related to take time off work to get vaccinated, 20 I I/I 2 vs $2013 / / 4$

\begin{tabular}{llll}
\hline Provider & $\begin{array}{l}\text { Change in no. of } \\
\text { vaccinations }\end{array}$ & $\begin{array}{l}\text { Hours taken off } \\
\text { work per vaccination }\end{array}$ & $\begin{array}{l}\text { Change in cost of time } \\
\text { invested (\$ million) }\end{array}$ \\
\hline Pharmacist & $+764,922$ & 0.00 & 0 \\
Physician & $-86,641$ & 0.85 & -1.91 \\
Public health nurse & $-155,697$ & 0.42 & -1.72 \\
Others & $-74,306$ & 0.42 & -0.82 \\
Total & $\mathbf{+ 4 4 8 , 2 7 8}$ & & $-\mathbf{4 . 4 5}$ \\
\hline
\end{tabular}

Table 5 Total change in annual costs following introduction of program

\begin{tabular}{ll}
\hline & $\begin{array}{l}\text { Change in } \\
\text { costs (\$) }\end{array}$ \\
\hline Vaccination costs $(+448,000$ vaccinations) & $+6,301,444$ \\
Direct health care costs related to influenza & $-763,158$ \\
Subtotal health care costs & $+\mathbf{5 , 5 3 8 , 2 8 6}$ \\
Productivity costs for time invested to get vaccinated & $-4,453,491$ \\
Productivity costs for time lost for influenza illness & $-3,420,585$ \\
Subtotal productivity costs & $-\mathbf{7 , 8 7 4 , 0 7 6}$ \\
Total change in costs & $\mathbf{- 2 , 3 3 5 , 7 9 0}$ \\
\hline
\end{tabular}

savings. Using the $2.5 \%$ and $97.5 \%$ percentiles of the PSA simulations, incremental costs of pharmacist-administered vaccinations ranged from increased costs of $\$ 2.46$ million to savings of $\$ 10.15$ million.

A tornado diagram showing the incremental costs (savings) when varying the values in the five one-way sensitivity analyses is presented in Figure 2.

As shown in Figure 2, the variables that had the biggest impact on the incremental cost estimates were the probability that a pharmacy-administered vaccination takes place during work hours, the probability of contracting influenza for those aged $<65$ years, the number of hours taken off if a person is sick with influenza, and the proportion of employed patients assumed to take time off work if they get influenza. The variables that are associated with productivity costs generally have a bigger impact on the results than variables that are not.

\section{Discussion}

After the introduction of the pharmacist-administered influenza vaccination program, there was an increase of almost 450,000 (3\%) Ontarians vaccinated compared to the influenza season before the program. This is consistent with data from other provinces in Canada that support the benefit of pharmacists' involvement in influenza vaccination programs. ${ }^{23-26}$ The increase in immunizations was associated with an increase of $\$ 6.3$ million in expenditure to pay for the incremental vaccines and their administration. However, this improvement in vaccination numbers potentially saved $\$ 0.7$ million in direct health care costs and $\$ 7.9$ million in productivity costs. This results in a potential overall saving of $\$ 2.3$ million. With a goal set by the Government of Canada to vaccinate $80 \%$ of all adults aged $\geq 65$ years and adults aged 18-65 years with chronic medical conditions by $2025,{ }^{27}$ the net increases in the number of individuals vaccinated against influenza that have been realized following the introduction of pharmacistadministered influenza vaccination programs represent an additional strategy to help achieve this target.

There are limitations to the analysis. First, we relied on billing claims data for influenza vaccination counts. These claims data collect information at an individual level; therefore, the composition of family units and other individuals sharing the same household could not be determined. 


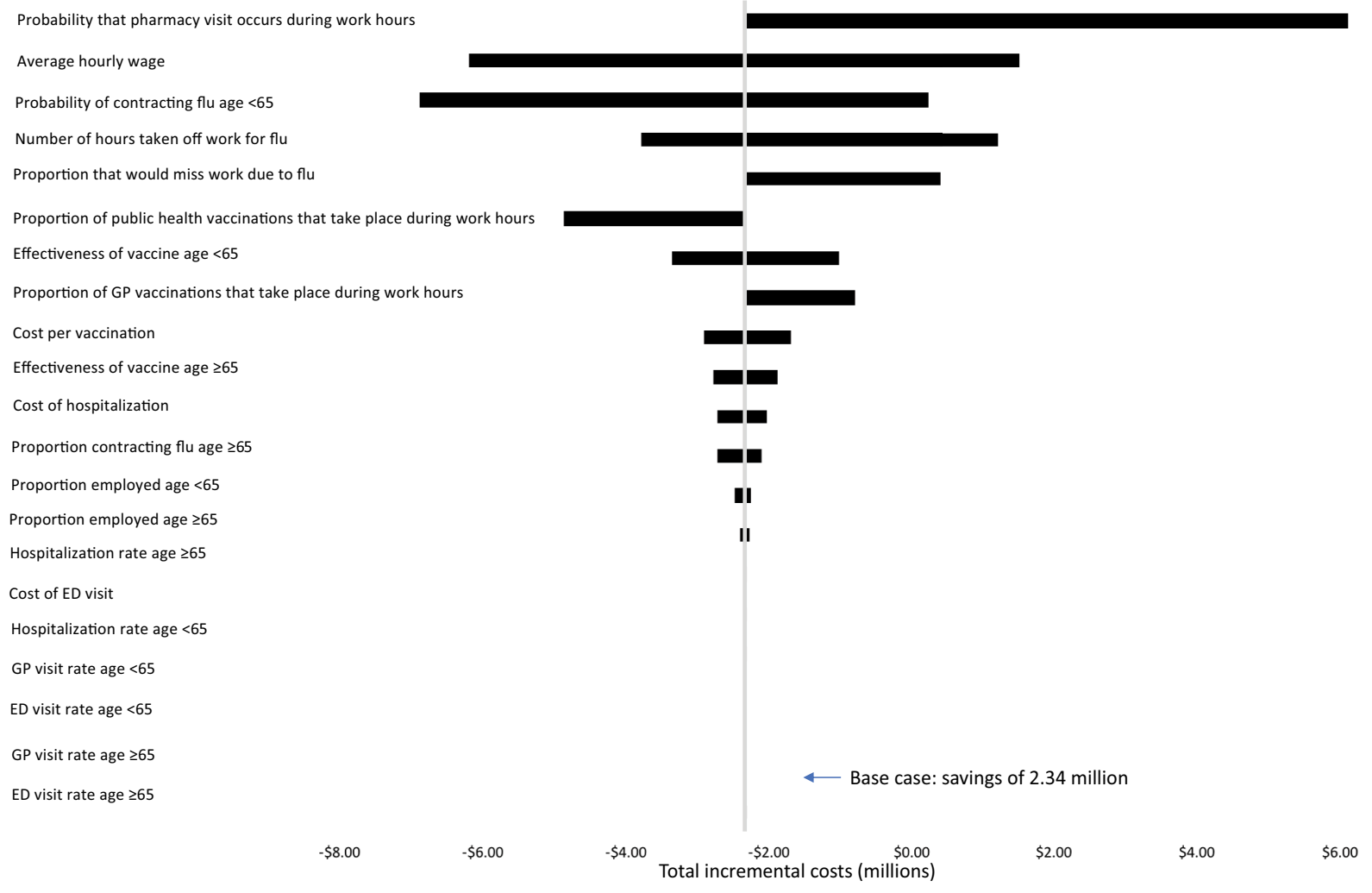

Figure 2 Tornado diagram comparing the relative importance of model parameters on estimated costs. Abbreviations: flu, influenza; GP, general practitioner; ED, emergency department.

A greater risk of exposure to the virus from an infected household member could not be accounted for. In addition, productivity losses incurred by parents and other caregivers to a child with influenza were not included in the model, thereby underestimating productivity losses reported in this study. A provincial review of the administrative data set used also estimated that approximately 1 million doses were not accounted for and were probably doses administered by nurses in Family Health Teams. ${ }^{28}$ In addition, the distribution data used in the data calculation did not account for any wastage (eg, doses drawn up in error, multi-dose vials that had to be discarded). Also, we did not have the ability to account for two doses required for immunizing younger children. The increased number of individuals seeking immunization may also have been influenced by deaths related to H1N1 reported in Canada in January 2014, ${ }^{29}$ thus providing a onetime increase in uptake that year. This economic analysis should be replicated with vaccination counts observed from the 2014/15 influenza season onward to account for annual shifts in vaccination rates. At the time of writing, more recent data have not been published. The cost of the vaccine dose was also based on an average estimated price and discount and is an estimate of the actual cost to the Province of Ontario.
Furthermore, given that we used modeling techniques to estimate the change in costs associated with the increase in influenza vaccinations, a number of assumptions were made using published data from the literature for risk variables, outcomes, and productivity costs. We used various scenario analyses and sensitivity analyses to explore the impact of these assumptions on the results.

Furthermore, this evaluation did not consider the fact that influenza is an infectious disease and easily transmitted from one person to another. For example, if more people were vaccinated there would be benefits for those who do not get vaccinated, resulting in fewer infections, leading to fewer days off work and less health care resource utilization. As a result, it is possible that the cost estimates found in this study are an underestimate of the true cost savings.

As of December 2016, nine of the ten provinces in Canada, but none of the three territories, had passed legislation that allowed pharmacists with appropriate certification to administer select vaccinations, including influenza vaccine. ${ }^{30}$ As of 2016, approximately, 9,229 of the 14,824 Part A pharmacists in Ontario had obtained certification. ${ }^{31}$

To the best of our knowledge, this study is the first to estimate the economic impact of the introduction of the 
pharmacist-administered influenza program in Ontario. Uptake of this service by younger adults is likely to reflect the convenience of receiving vaccinations from community pharmacists. While these individuals may be at lower risk of hospitalization or death from influenza than older patients, costs due to lost productivity can be significant and demonstrate a societal benefit of convenient access to a UIIP including community pharmacists. The observed productivity benefits are significant at the individual patient level, relating to one's ability to work and perform other necessary duties, at the health care provider level, by ensuring the availability of a healthy workforce to provide essential health services and reduced resource expenditure on influenza-related visits and sick-note documentation, and at the societal level, by minimizing the impact of influenza illness across all sectors. As influenza season recurs annually, even small impacts observed each year could translate to billions in productivity saved over a few years as pharmacist-administered influenza immunization programs continue to be introduced nationwide.

\section{Conclusion}

The policy of allowing pharmacists to administer influenza vaccinations was associated with an increase in vaccine uptake and a decrease in influenza-related health care resource utilization and costs. When productivity costs are taken into account, the investment in the additional vaccinations was cost saving.

\section{Acknowledgments}

The authors acknowledge study coordination support provided by Richard Violette and Dana Church of the Ontario Pharmacy Evidence Network (OPEN), School of Pharmacy, University of Waterloo. This work was conducted with the support of OPEN, which received funding from the Neighbourhood Pharmacy Association of Canada (NPAC).

\section{Author contributions}

Each author meets the International Committee of Medical Journal Editors' criteria for authorship and has read and approved the final manuscript. DJOR and GB: conception and design of the study, analysis and interpretation of the data, and drafting the manuscript. SB, JMB, and NB: collection of the data, interpretation of data, and critically revising the manuscript for important intellectual content. JM, NMW, and SKDH: conception and design of the study, interpretation of the data, and critically revising the manuscript for important intellectual content. All authors contributed to data analysis, drafting and revising the article, gave final approval of the version to be published, and agree to be accountable for all aspects of the work.

\section{Disclosure}

The results of this study have been presented at the following conferences:

1. O'Reilly D, Blackhouse G, Burns S, et al. Economic analysis of community pharmacists providing influenza vaccination in Ontario. 2016 Canadian Immunization Conference, Ottawa, ON, December 6-8, 2016. (Oral presentation)

2. O'Reilly D, Blackhouse G, Burns S, et al. Economic analysis of pharmacist-administered influenza immunizations in Ontario. CADTH Symposium, Ottawa, ON, April 23-25, 2017. (Oral presentation)

3. Houle SKD, O'Reilly D, Blackhouse G, et al. Economic analysis of community pharmacists providing influenza vaccination in Ontario. Can Pharm J. 2017;150(4):S31. https://www.pharmacists.ca/cpha-ca/assets/File/newsevents/Conference/2017/Research/CPJSupplementAbstractsPosters 17.pdf (Published abstract)

4. Houle SKD, O'Reilly D, Blackhouse G, Burns S, et al. Economic analysis of community pharmacists providing influenza vaccination in Ontario. North American Primary Care Research Group Annual Meeting, Montreal, QC, November 17-21, 2017. (Poster)

5. O'Reilly D, Blackhouse G, Burns S, et al. Economic analysis of community pharmacists providing influenza vaccination in Ontario. OPEN 2016 Research Showcase. School of Pharmacy, University of Waterloo. November 7, 2016. http://www.open-pharmacy-research.ca/ events/2016-research-showcase/oral-presentations/

JM is employed by the Neighbourhood Pharmacy Association of Canada, which provided funding for this project. The authors report that they have no other conflicts of interest in this work.

\section{References}

1. Canadian Public Health Agency [webpage on the Internet]. Immunize Canada. Ottawa (ON): Immunize Canada; 2017. Available from: http:// www.immunize.ca/en/diseases-vaccines/influenza.aspx. Accessed September 6, 2018.

2. Dahrouge S, Devlin R, Hogg B, Russell G, Coyle D, Fergusson D. The Economic Impact of Improvements in Primary Healthcare Performance. Ottawa (ON): Canadian Health Services Research Foundation; 2012.

3. Statistics Canada [webpage on the Internet]. Estimates of population, by age group and sex for July 1, Canada, provinces and territories, annual (persons unless otherwise noted), CANSIM (database) Table 051-0001. Ottawa: Statistics Canada; 2016. Available from: http://www5.statcan. gc.ca/cansim/a26?id=510001. Accessed September 6, 2018.

4. Ontario College of Pharmacists. Expanded Scope regulation now in effect. Pharmacy Connection. 2012;19(4):12-21.

5. Government of Ontario [webpage on the Internet]. Progress Report 2014: Health Care. Toronto (ON): Queen's Printer for Ontario; 2014. Available from: http://www.ontario.ca/page/progress-report2014-health-care. Accessed February 24, 2017. 
6. Ontario College of Pharmacists [webpage on the Internet]. New Authority for Vaccinations Now in Effect. Toronto (ON): Ontario College of Pharmacists; 2016. Available from: http://us14.campaign-archive1. com $/$ ?u=e07deeda974b0e8dc66be702b\&id=ba877f9350\&e=779bf 87 07c. Accessed April 22, 2017.

7. Kwong JC, Cadrette S, Schneider E, Campitelli M, Church D, Consiglio G. Community pharmacies providing influenza vaccine in Ontario: a descriptive analysis using administrative data. Canadian Pharmacists Conference. Ottawa; 2015.

8. Ontario Pharmacy Evidence Network (OPEN). Wins \& Needles: How Pharmacists Give Influenza Vaccination a Shot in the Arm Waterloo; 2015. Available from: http:/www.open-pharmacy-research.ca/wordpress/ wp-content/uploads/wins-and-needles.pdf. Accessed September 6, 2018.

9. Ontario Ministry of Health and Long Term Care. Schedule of Benefits - Physician Services Under the Health Insurance Act. Toronto (ON): Queen's Printer for Ontario; 2015.

10. Ontario Public Drug Programs. Notice from the Executive Officer: Pharmacist Administration of Publicly Funded Influenza Vaccine and Claims Submission using the Health Network System - For the 2015 2016 Influenza Immunization Season. Toronto (ON): Ministry of Health and Long Term Care; 2016. Available from: http://www.health.gov.on.ca/ en/pro/programs/drugs/opdp_eo/notices/eo_flu_mist_20151013.pdf. Accessed September 6, 2018.

11. Ontario Ministry of Health and Long Term Care. Universal Influenza Immunization Program (UIIP). Toronto (ON): Queen's Printer for Ontario; 2016. Available from: http://www.health.gov.on.ca/en/pro/ programs/publichealth/flu/. Accessed September 6, 2018.

12. Ontario Agency for Health Protection and Promotion (Public Health Ontario). Influenza and Respiratory Infection Surveillance Summary Report: 2012-13 season. Toronto (ON): Queen's Printer for Ontario; 2015. Available from: http://www.publichealthontario.ca/ en/eRepository/Influenza_Respiratory_Infection_Surveillance_Summary_Report_2012_13.pdf. Accessed September 6, 2018.

13. Ontario Agency for Health Protection and Promotion (Public Health Ontario). Ontario Respiratory Virus Bulletin 2013-2014: Surveillance Season (September 1, 2013-August 31, 2014). Toronto (ON): Queen's Printer for Ontario; 2015. Available from: http://www.publichealthontario. ca/en/DataAndAnalytics/Documents/Ontario_Respiratory_Virus_Bulletin-2013-2014_Season_Summary.pdf. Accessed September 6, 2018.

14. Ontario Agency for Health Protection and Promotion (Public Health Ontario). Ontario Respiratory Virus Bulletin 2014-2015: Surveillance Season (September 1, 2014-August 31, 2015). Toronto (ON): Queen's Printer for Ontario; 2016. Available from: http://www.publichealthontario. ca/en/DataAndAnalytics/Documents/Ontario_Respiratory_Virus_Bulletin-2014-2015_Season_Summary.pdf. Accessed September 6, 2018.

15. Prosser LA, O'Brien MA, Molinari NA, et al. Non-traditional settings for influenza vaccination of adults: costs and cost effectiveness. Pharmacoeconomics. 2008;26(2):163-178.

16. Sander B, Kwong JC, Bauch CT, et al. Economic appraisal of Ontario's Universal Influenza Immunization Program: a cost-utility analysis. PLoS Med. 2010;7(4):e1000256.

17. Statistics Canada [webpage on the Internet]. Consumer Price Index, health and personal care, by province (Canada). Ottawa: Statistics Canada. Available from: http://www.statcan.gc.ca/tables-tableaux/ sum-som/101/cst01/econ161a-eng.htm. Accessed June 15, 2016.
18. Region of Waterloo Public Health. Health in Action. Fall 2011/Winter 2012.

19. Region of Waterloo Public Health. Health in Action. Fall 2012/Winter 2013.

20. Statistics Canada [webpage on the Internet]. Labour Force Survey estimates (LFS), by sex and detailed age group, annual (persons unless otherwise noted), CANSIM Table 282-0002. Ottawa: Statistics Canada. Available from: http://www5.statcan.gc.ca/cansim/a26?lang $=$ eng\&retrLang=eng\&id=2820002\&pattern $=\&$ csid $=$. Accessed June $12,2016$.

21. Ray KN, Chari AV, Engberg J, Bertolet M, Mehrotra A. Opportunity costs of ambulatory medical care in the United States. Am J Manag Care. 2015;21(8):567-574.

22. Schanzer DL, Zheng H, Gilmore J. Statistical estimates of absenteeism attributable to seasonal and pandemic influenza from the Canadian Labour Force Survey. BMC Infect Dis. 2011;11:90.

23. Poulose S, Cheriyan E, Cheriyan R, Weeratunga D, Adham M. Pharmacist-administered influenza vaccine in a community pharmacy: A patient experience survey. Can Pharm J. 2015;148(2):64-67.

24. Isenor JE, Killen JL, Billard BA, et al. Impact of pharmacists as immunizers on influenza vaccination coverage in the community-setting in Nova Scotia, Canada: 2013-2015. J Pharm Policy Pract. 2016; $9: 32$.

25. Isenor JE, Alia TA, Killen JL, et al. Impact of pharmacists as immunizers on influenza vaccination coverage in Nova Scotia, Canada. Hum Vaccin Immunother. 2016;12(5):1225-1228.

26. Buchan SA, Rosella LC, Finkelstein M, et al. Impact of pharmacist administration of influenza vaccines on uptake in Canada. CMAJ. 2017;189(4):E146-E152.

27. Government of Canada. Vaccination Coverage Goals and Vaccine Preventable Disease Reduction Targets by 2015. Ottawa: Government of Canada; 2015. Available from: https://http://www.canada.ca/en/ public-health/services/immunization-vaccine-priorities/national-immunization-strategy/vaccination-coverage-goals-vaccine-preventablediseases-reduction-targets-2025.html. Accessed June 19, 2018.

28. Ministry of Health and Long-term Care. Chapter 3.04 Immunization. Annual Report of the Office of the Auditor General of Ontario. Toronto (ON): Queen's Printer for Ontario; 2014:155-192.

29. Mcknight $Z$. Two confirmed deaths in Toronto from H1N1 flu. The Star. 2014. Available from: https:/www.thestar.com/news/gta/2014/01/03/ two_confirmed_deaths_in_toronto_from_h1n1flu.html. Accessed September 21, 2018.

30. Canadian Pharmacists Association. Pharmacist's Scope of Practice in Canada; 2017. Available from: http://www.pharmacists.ca/cpha-ca/ assets/File/cpha-on-the-issues/ScopeofPracticeinCanada_DEC2016. pdf. Accessed February 27, 2017.

31. Poon M. Manager, Information Management. Toronto (ON): Ontario College of Pharmacists; 2017.

32. Statistics Canada [webpage on the Internet]. Labour Force Survey estimates (LFS), wages of employees by job permanence, union coverage, sex and age group, unadjusted for seasonality, monthly (current dollars unless otherwise noted), CANSIM (database). Table 282-0073. Ottawa: Statistics Canada. Available from: http:/www5.statcan.gc.ca/ cansim/a26?lang=eng\&id=2820073. Cited February 2016. Accessed September 6, 2018.

\section{ClinicoEconomics and Outcomes Research}

\section{Publish your work in this journal}

ClinicoEconomics and Outcomes Research is an international, peerreviewed open-access journal focusing on health technology assessment, pharmacoeconomics and outcomes research in the areas of diagnosis, medical devices, and clinical, surgical and pharmacological intervention. The economic impact of health policy and health systems organization also constitute important areas of coverage. The manuscript management system is completely online and includes a very quick and fair peer-review system, which is all easy to use. Visit http://www.dovepress.com/testimonials.php to read real quotes from published authors. 